\begin{tabular}{|c|l|}
\hline Title & Critical heat flux on a vertical surface in saturated pool boiling at high pressures \\
\hline Author(s) & Sakashita, Hiroto \\
\hline Citation & Journal of thermal science and technology, 11(2), 16-264 \\
\hline https://doi.org/10.1299/tst.2016jtst0020 \\
\hline Issue Date & 2016-08-31 \\
\hline Doc URL & http://hdl.handle.net/2115/64780 \\
\hline Rights & (2016.The Japan Society of Mechanical Engineers \\
\hline Type & article (author version) \\
\hline File Information & (final) JSME (J.thermal Sci and Tech).pdf \\
\hline
\end{tabular}

Instructions for use 


\title{
Critical heat flux on a vertical surface in saturated pool boiling at high pressures
}

\author{
Hiroto SAKASHITA* \\ * Division of Energy and Environmental Systems, Hokkaido University \\ North 13 West 8, Kita-ku, Sapporo 060-8628, Japan \\ E-mail: saka@eng.hokudai.ac.jp
}

Received ** May 2016

\begin{abstract}
This paper investigates the CHF in saturated pool boiling of ethanol, R141b, and water on a $7 \mathrm{~mm}$ diameter vertical copper surface at high pressures. The pressures are from 0.1 to $3 \mathrm{MPa}$ for ethanol, 0.1 to $1.5 \mathrm{MPa}$ for R141b, and 0.1 to $0.8 \mathrm{MPa}$ for water. The results show that the occurrence of CHF is accompanied by the formation of large vapor masses covering most of the heating surface with all three liquids over the whole range of pressures investigated here. The well-known Kutateladze-type CHF correlation explains the variations in the CHF with pressure well for ethanol and R141b, and underestimates the pressure dependence of the CHF for water. A correlation considering the effect of surface wettability on the CHF agrees fairly well with the $\mathrm{CHF}$ for water in the whole range of pressures here, when the temperature dependence of the contact angle determined from available data is incorporated into the correlation. This suggests that it is necessary to consider changes in surface wettability with pressure to be able to predict the CHF of water at high pressures.
\end{abstract}

Key words : Critical heat flux, Pool boiling, High pressure, Wettability, Experiment

\section{Introduction}

Accurate predictions of the critical heart flux (CHF) are vital for safety assessments of thermal devices with high heat flux components. A large number of studies have been conducted and a number of mechanisms responsible for the occurrence of CHF have been proposed. For the CHF of saturated pool boiling, Kutateladze (1952) assumed that the CHF is a purely hydrodynamic phenomenon and that it is triggered by a destruction of the stability of the two phase flow occurring close to the heating surface, and derived Eq. (1) for the CHF on upward facing large surfaces based on a dimensional analysis.

$$
q_{C H F}=K \cdot \rho_{v}^{1 / 2} H_{f g}\left[\sigma g\left(\rho_{l}-\rho_{v}\right)\right]^{1 / 4}
$$

where $K$ is an unknown constant. Kutateladze gives $K$ as 0.13 to 0.19 depending on the kind of boiling liquid, by comparing Eq. (1) with the available data measured for various liquids. Zuber (1959) derived Eq. (1) theoretically for the CHF of infinitely large upward facing surfaces, based on a hydrodynamic instability model in which Helmholtz instability at the interface between vapor jets and the surrounding liquid is the cause of the CHF. In Zuber's model, the constant $K$ is determined theoretically as 0.131. Lienhard and Dhir (1973) modified the Zuber model and recommended the constant $K$ in Eq. (1) as $K=0.149$ for CHF of large upward surfaces. Katto and Yokoya (1968) proposed a macrolayer dryout model in which the CHF occurs when a liquid layer (a so-called macrolayer) formed beneath a large vapor mass dries out just before the departure of the vapor mass. This model was further developed and formulated by Haramura and Katto (1983), and here the CHF for large upward surfaces is given in the same form as Eq. (1) with $K=0.131$.

In addition to the above models, There are various other CHF models; the dry-spot model by Unal et al. (1992), Theofanous et al. (2002), and Ha and Ma (1998); the triple contact line density model by Nishio et al. (1998); the stationary vapor stem model by Dhir and Liaw (1987); the interfacial lift-off model by Howard and Mudawar (1999); 
and the microlayer model by Zhao et al. (2002). (In addition to these models, Kandlikar (2001) proposed a CHF model which will be taken up in Section 3.2.)

In experimental research, numerous studies have been conducted during the past several decades, and valuable CHF data have been accumulated for various boiling conditions, however, most of these studies are carried out around atmospheric pressure, and studies at higher pressures are relatively few. Cichelli and Bonilla (1949) measured the CHF of ethanol and four different hydrocarbons (n-pentane, n-heptane, propane, and benzene) with a 95mm diameter upward facing horizontal surface over a wide range of pressures. Kutateladze (1952) compared the data by Cichelli and Bonilla with Eq. (1) and found that the data are well correlated with Eq. (1) when the constant $K$ is fitted to the different liquids in the range of $K=0.13$ to 0.19 . Bewilogua et al. (1975) measured the CHF of cryogens (nitrogen, hydrogen, and helium) on 19.2 and 25 mm diameter upward facing disks in a wide range of pressures up to near the critical pressures. The data for nitrogen and hydrogen agree well with Eq. (1) and $K=0.16$, and the data of helium with $K=0.22$. Bewilogue et al. also measured the CHF of helium on inclined surfaces by varying the angle of inclination from $0^{\circ}$ (horizontal upward facing) to $165^{\circ}$ (facing almost horizontally downward) and showed that the relative dependence of the CHF on the pressure is explained fairly well with Eq. (1). Deev et al. (1977) measured the CHF of helium on a $30 \times 30 \mathrm{~mm}$ upward square surface in the range of reduced pressures of $0.44<P / P c<0.98$, and showed that the data for $P / P c<0.75$ agree well with Eq. (1) and $K=0.22$, similar to the results by Bewilogua et al. (1975).

For the CHF of water, Kazakova (1949, 1950, 1953) carried out experiments with horizontal wires with diameters of $0.135,0.15$, and $0.29 \mathrm{~mm}(1949,1950)$ and with a $5 \mathrm{~mm}$ wide horizontal ribbon with both sides heated (1953), in the wide range of pressures up to near the critical pressure. Sakashita and Ono (2009) measured the CHF of water on an upward facing surface with $4 \mathrm{~mm}$ wide and $20 \mu \mathrm{m}$ thick nichrome foil at pressures from 0.1 to 7 MPa. Figure 1 shows the data by Kazakova (1949, 1950, 1953) and Sakashita and Ono (2009), together with the results predicted with Eq. (1) by Zuber $(K=0.131)$ and Lienhard and Dhir $(K=0.149)$. As for the data by Kazakova, the CHF of the horizontal ribbon with both sides heated plot around the predicted curves with the Eq. (1) by Zuber, and Lienhard and Dhir, however, the CHF of horizontal wires scatter considerably. It is well known that the CHF of fine wires vary in a complicated manner dependent on the wire diameter (Lienhard and Watabnabe, 1966, Sun and Lienhard, 1970), and this may be one of the causes of the scatter in the data with wires by Kazakova. The data by Sakashita and Ono plot considerably higher than the predictions with Eq. (1) at higher pressures, but scatter widely probably due to the small heat capacity and low thermal diffusivity of the thin $(20 \mu \mathrm{m})$ nichrome heating surface. Further, according to the previous research (e.g. Houchin and Lienhard (1966), Tachibana et al. (1967), and Golobic and Bergles (1997)), the CHF is greatly affected by thermal properties of heating surface, such as thickness, thermal conductivity and specific heat. Arik and Bar-Cohen (2003) presented that the CHF decreases with the decrease in the parameter $S$ (= $\delta \sqrt{\rho_{h} C_{p h} k_{h}}$ ) when $S$ is smaller than 5 to 10 . The value of $S$ of the heating surface used by Sakashita and Ono is 0.164 , suggesting that this CHF data may include an effect of the parameter $S$.

As above, the pressure dependence of CHF for ethanol, hydrocarbons, and cryogens measured with thick metal heaters of various sizes and orientations are expressed well with Eq. (1) derived for infinitely large upward surfaces. Still, for the CHF of water, further studies are necessary to examine whether Eq. (1) can be applied at higher pressures.
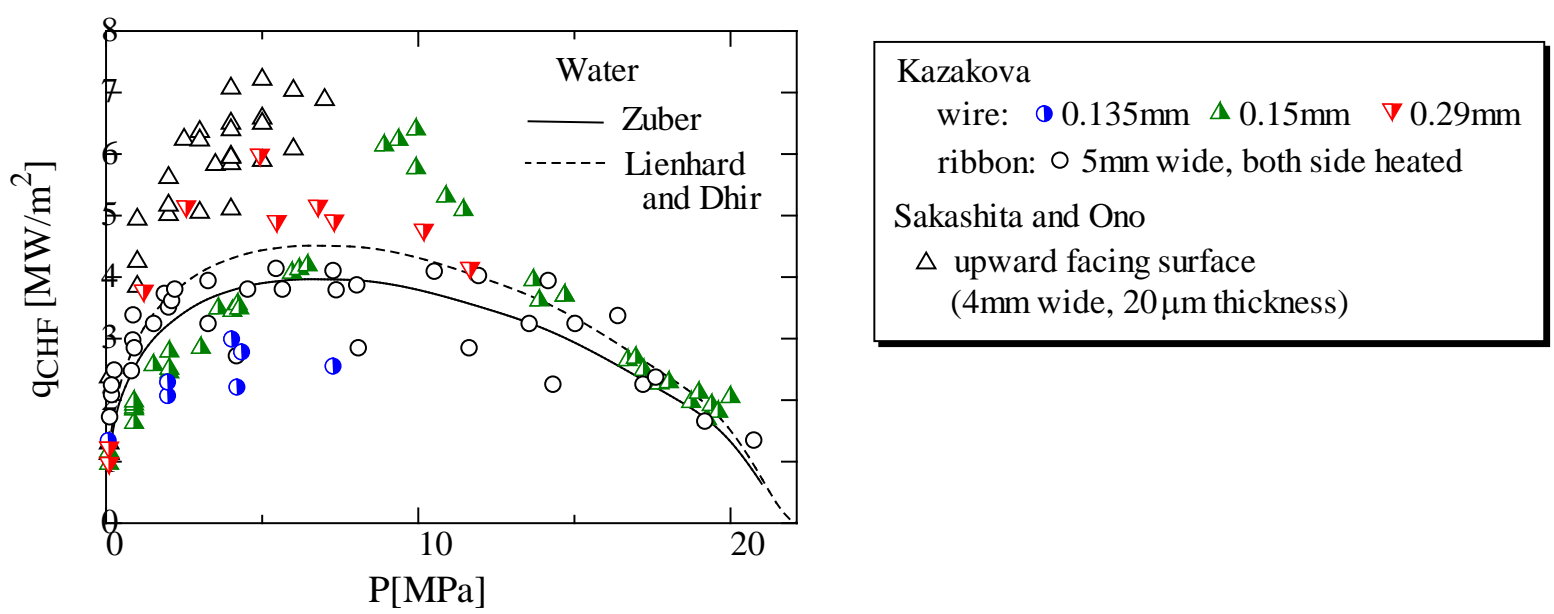

Fig.1 CHF of water measured by Kazakova (1949, 1950, 1953), and Sakashita and Ono (2009) 
Further, to better understand the CHF mechanism at higher pressures, it is vital to observe the boiling behaviors at high heat fluxes close to the CHF.

The study reported here measured the CHF of saturated pool boiling of ethanol, R141b, and water on a vertically oriented $7 \mathrm{~mm}$ diameter copper surface with large heat capacity (large $S$ value) at high pressures, and observed the boiling behaviors from low heat fluxes till CHF. Further, the effect on the CHF of surface wettability for water that changes with pressure is examined by comparing the measured data with the available CHF correlations considering the effect of surface wettability.

\section{Nomenclature}

$C_{p} \quad$ specific heat

$g$ gravitational acceleration

$H_{f g} \quad$ latent heat of vaporization

$K \quad$ constant in Eq. (1)

$k \quad$ thermal conductivity

$P \quad$ pressure

$P_{c} \quad$ critical pressure

$q \quad$ heat flux

$q_{\mathrm{CHF}} \quad$ critical heat flux

$S \quad$ parameter related to thermal properties of heating surface, $\delta \sqrt{\rho_{h} C_{p h} k_{h}}$

$T$ temperature

$T_{\mathrm{w}} \quad$ surface temperature

\section{Greek symbols}

$\beta \quad$ dynamic receding contact angle

$\Delta T_{\text {sat }} \quad$ surface superheat

$\delta \quad$ heater thickness

$\theta \quad$ static contact angle

$\phi \quad$ angle of inclination of the surface

$\rho$ density

$\sigma \quad$ surface tension

\section{Subscript}

h heater material

l liquid

v vapor

\section{Experiment}

The experiments were carried out in saturated boiling for ethanol at pressures of 0.1 to $3 \mathrm{MPa}\left(P / \mathrm{PC}_{C}=0.016\right.$ to $0.489)$, for $\mathrm{R} 141 \mathrm{~b}$ at 0.1 to $1.2 \mathrm{MPa}\left(P / P_{C}=0.024\right.$ to 0.285$)$, and for water at 0.1 to $0.8 \mathrm{MPa}\left(P / P_{C}=0.0045\right.$ to 0.036$)$.

Figure 2 shows the heating module used in the present experiments. One end of a copper rod served as the heating surface and it was heated with a cartridge heater inserted into the copper rod. The diameter of the heating surface was 7 mm with three sheathed-thermocouples ( $0.5 \mathrm{~mm}$ diameter) embedded 5, 12, and $19 \mathrm{~mm}$ below the heating surface to determine the surface temperature and surface heat flux. The copper rod was in a cylindrical stainless steel housing unit, and the surfaces of the copper and the surrounding 1mm thick stainless steel flange (the end surface of the housing unit) were machined to be flush, then plated with Ni (about $3 \mu \mathrm{m}$ thick) over the two surfaces to avoid corrosion and nucleation of bubbles at the interface between the copper surface and the surrounding flange.

The surface temperature and the surface heat flux were calculated from the three thermocouples embedded in the copper rod from the linear regression. The error come from non-uniformity of the heat flux on copper surface, which is brought about by the heat conduction through the surrounding stainless steel flange, was estimated by solving the 2-D 


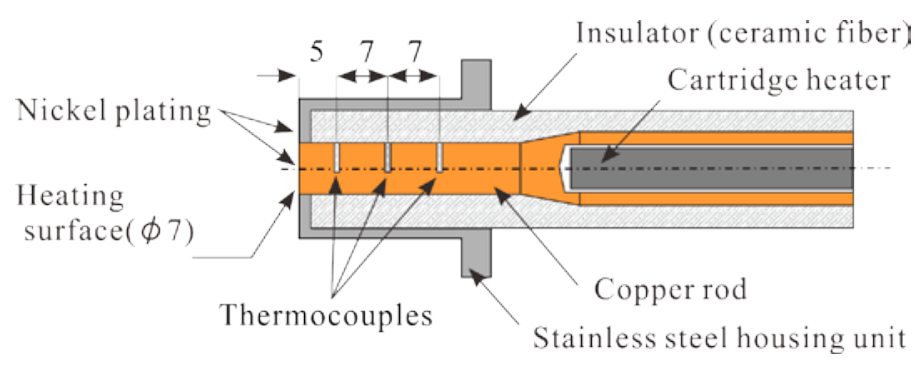

Fig. 2 Heating module

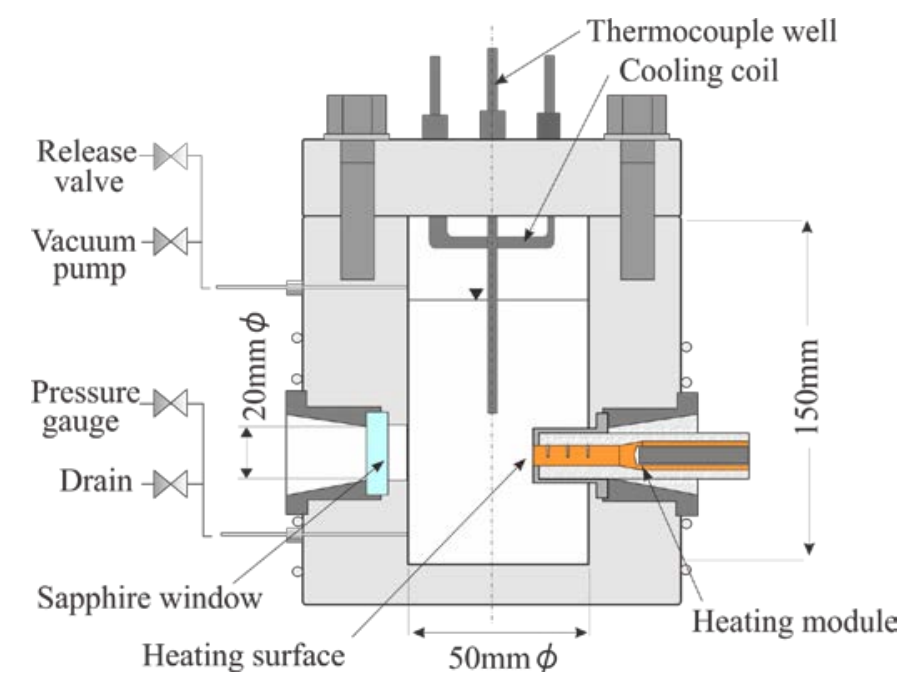

Fig. 3 High pressure cell

heat conduction equation. The boiling heat flux calculated with the correlation by Stephan and Abdelsalam (1980) was used as the boundary condition on the surface (copper and stainless steel flange). The difference between the heat flux at center of the heating surface to the heat flux averaged over the copper heating surface was less than $6 \%$., and therefore, it was assumed that the error of the heat flux estimated with three thermocouples was also less than 6\%. For water boiling at high heat fluxes and high pressures, the bottom part of the copper heating module reaches very high temperatures due to the increases in the CHF and the saturation temperature with the increase in pressure. Therefore, the present experiments with water boiling was carried out at 0.8MPa or lower pressures, to avoid failure of the cartridge heater inserted in the heating module.

Figure 3 shows the high pressure cell, it is cylindrical with an inner diameter of $50 \mathrm{~mm}$ and a height of $150 \mathrm{~mm}$. The heating module shown in Fig. 2 was inserted in the cell from the side of the cell, and a sapphire window was provided in the opposite side of the cell. The boiling behaviors on the vertical heating surface were observed via the sapphire window using high speed video with a maximum $8000 \mathrm{fps}$ and a microscope with a maximum 320-fold magnification. The liquid temperature during the measurements was monitored with a sheathed thermocouple inserted in the thermocouple well, placed $11 \mathrm{~mm}$ above the upper edge of the heating surface.

The experiments were carried out in the following manner: before each experiment, the heating module was detached from the high pressure cell, and the heating surface was polished by emery paper (\#2000), washed with acetone and de-ionized water, and then reattached to the cell. Then, the high pressure cell was filled with the working fluid (de-ionized water with electrical conductivity less than $0.2 \mu \mathrm{S} / \mathrm{cm}$, ethanol of a purity of at least $99.5 \%$, or R141b with industrial grade purity) and decompressed with a vacuum pump to boil it at room temperature. This decompressed boiling was continued for about half an hour to ensure that the liquid was fully degassed, then the liquid was heated to a saturation temperature at a set pressure level by heater wires wound around the high pressure cell and maintained at that temperature by adjusting the input to the heaters and the flow rate of the cooling water through the cooling coils. Then, the heating module was heated with the cartridge heater, and the boiling curves were recorded at stepwise increasing heat input to the cartridge heater in the copper heating module. When approaching the CHF, the size of the 

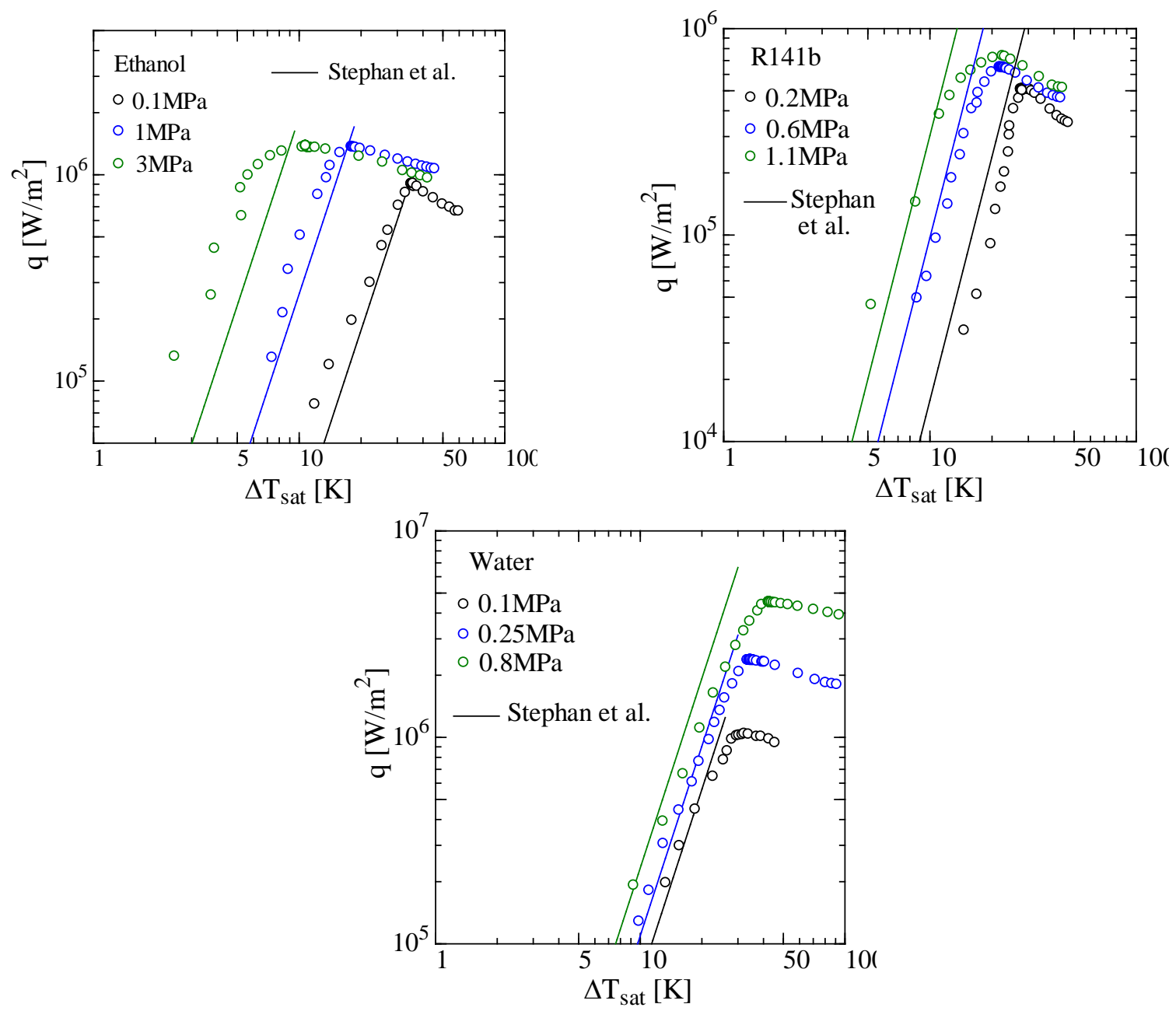

Fig. 4 Boiling curves for ethanol, R141b, and water at three different pressures

increments in the heat input was reduced, and the heat flux when the surface temperature was raised rapidly was defined as the CHF. During each experiment, the bulk temperature of the liquid was maintained within $\pm 0.5 \mathrm{~K}$ of the set saturation temperature. The uncertainties in the saturation pressure caused by this temperature uncertainty increased with the saturation pressure and were estimated to be lower than $\pm 0.01 \mathrm{MPa}$ for R141b and water, and $\pm 0.03 \mathrm{MPa}$ for ethanol.

\section{Experimental results \\ 3.1 Boiling curves and boiling behaviors}

Figure 4 shows the boiling curves for ethanol, R141b, and water at three different pressures. The data in the nucleate boiling regions were obtained under steady state conditions and the data in the transition boiling regions were under a transient mode. Figure 4 also shows the predicted results with the Stephan and Abdelsalam (1980) correlation. Although there are discrepancies between the data and the predictions for ethanol at $3 \mathrm{MPa}$, the other data agree fairly well with the results of the Stephan and the Abdelsalam correlation.

Figure 5 shows the changes in boiling behaviors with heat fluxes for R141b at 1.0 MPa. (The 7 mm diameter heating surface is encircled by a broken line in Fig. 5-(h).) The fine primary bubbles generated at low heat flux (Fig. 5-(a)) coalesce and form small coalesced bubbles (Fig. 5-(b)). These coalesced bubbles coalesce further to form large coalesced bubbles with increases in the heat flux (Figs. 5-(c) to (f)). With further increases in the heat flux, the large coalesced bubbles grow to large vapor masses with sizes closer to that of the heating surface (Fig. 5-(g)), then the CHF is reached. Figures 5-(g) and 5-(h) show the boiling behaviors just before $(\mathrm{CHF}(-))$ and after $(\mathrm{CHF}(+))$ the $\mathrm{CHF}$, respectively. It is confirmed that almost all of the heating surface is covered with a large vapor mass at the $\mathrm{CHF}$ 


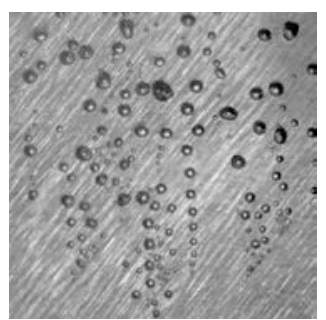

(a) $\mathrm{q}=0.017 \mathrm{MW} / \mathrm{m}^{2}$

(0.02CHF)

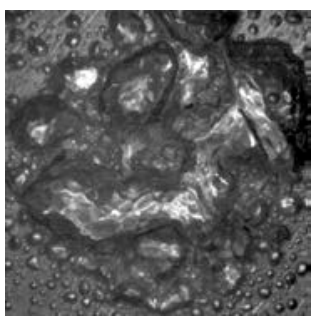

(e) $\mathrm{q}=0.63 \mathrm{MW} / \mathrm{m}^{2}$ (0.76CHF)

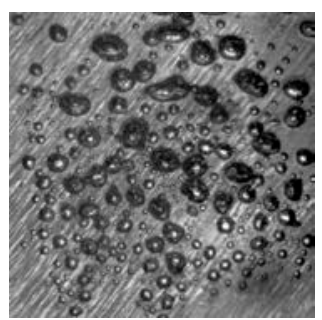

(b) $\mathrm{q}=0.066 \mathrm{MW} / \mathrm{m}^{2}$ (0.08CHF)

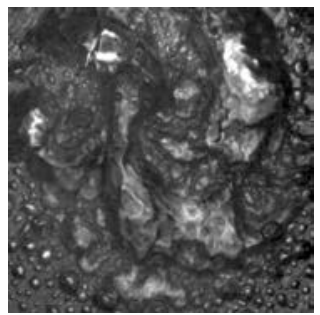

(f) $q=0.75 \mathrm{MW} / \mathrm{m}^{2}$ (0.91CHF)

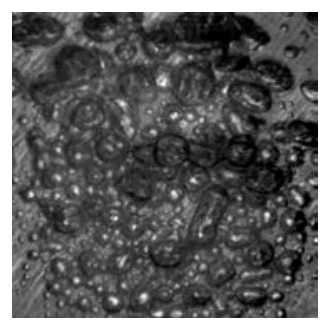

(c) $q=0.21 \mathrm{MW} / \mathrm{m}^{2}$ (0.26CHF)

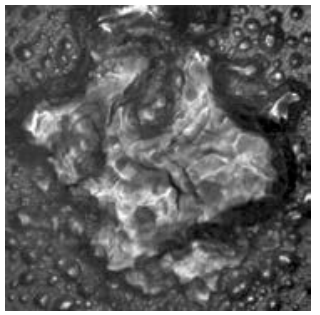

(g) $\mathrm{q}=0.82 \mathrm{MW} / \mathrm{m}^{2}$ (CHF(-))

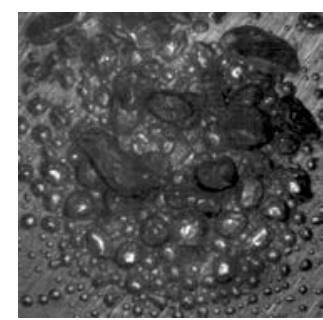

(d) $\mathrm{q}=0.35 \mathrm{MW} / \mathrm{m}^{2}$ (0.42CHF)

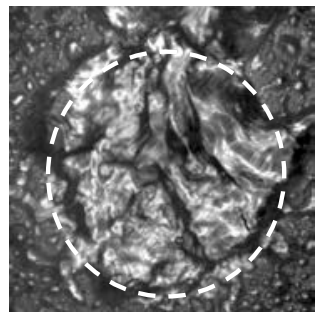

(h) $\mathrm{q}=0.82 \mathrm{MW} / \mathrm{m}^{2}$ $(\mathrm{CHF}(+))$

Fig. 5 Changes in boiling appearance with heat flux for boiling of R141b at 1MPa

condition. Further, from the video records (although not clear from Fig. 5-(h)), it was observed that almost all of the surface was dried out just after the CHF. The boiling behaviors for ethanol were similar to those of R141b: The coalesced bubbles increased in size with the increase in the heat flux and vapor masses large enough to cover the heating surface appeared near the CHF. Further, dryout of the heating surface was observed just after the occurrence of the CHF.

Figure 6 shows the changes in boiling behaviors with increasing heat flux for water at $0.8 \mathrm{MPa}$. (The $7 \mathrm{~mm}$ diameter heating surface is outlined by the broken line in Fig. 6-(g).) The larger bubbles appearing in Fig. 6-(a) are the coalesced bubbles formed by the coalescence of the primary bubbles. These coalesced bubbles further coalesce with increases in the heat flux and a large vapor mass completely covering the heating surface is formed at $2.19 \mathrm{MW} / \mathrm{m}^{2}$ (Fig. 6-(f)). The size of the vapor mass at detachment increases with the increases in the heat flux (Figs. 6-(f) and (g)),

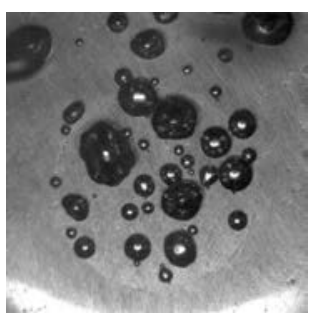

(a) $\mathrm{q}=0.19 \mathrm{MW} / \mathrm{m}^{2}$ (0.042CHF)

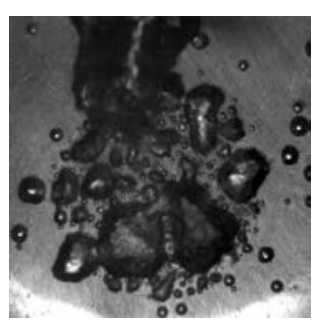

(e) $\mathrm{q}=1.64 \mathrm{MW} / \mathrm{m}^{2}$ (0.362CHF)

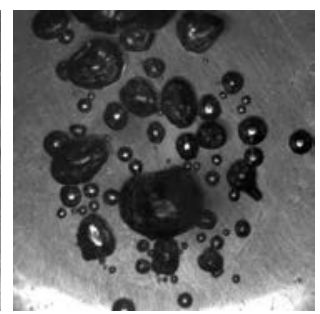

(b) $\mathrm{q}=0.39 \mathrm{MW} / \mathrm{m}^{2}$ (0.087CHF)

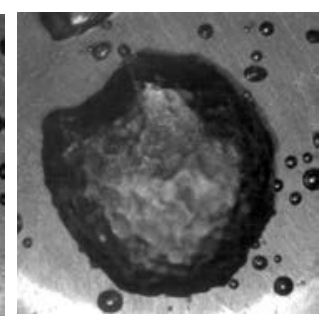

(f) $q=2.19 \mathrm{MW} / \mathrm{m}^{2}$ (0.482CHF)

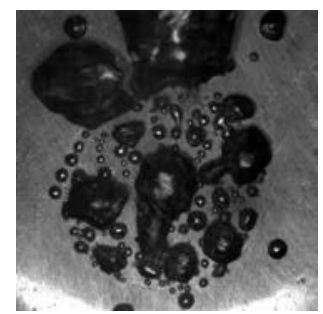

(c) $\mathrm{q}=0.66 \mathrm{MW} / \mathrm{m}^{2}$ (0.147CHF)

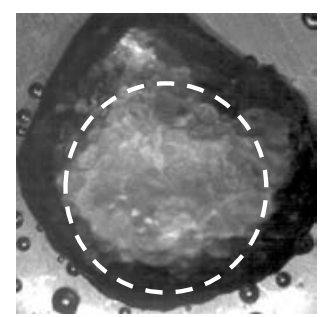

(g) $\mathrm{q}=4.10 \mathrm{MW} / \mathrm{m}^{2}$

(0.903CHF)

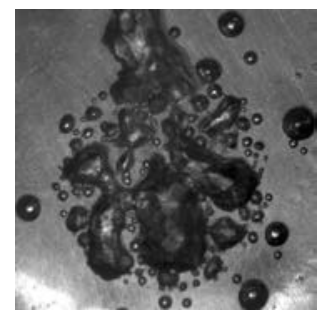

(d) $\mathrm{q}=1.11 \mathrm{MW} / \mathrm{m}^{2}$ (0.245CHF)

Fig. 6 Changes in boiling appearance with heat flux for boiling of water at $0.8 \mathrm{MPa}$ 


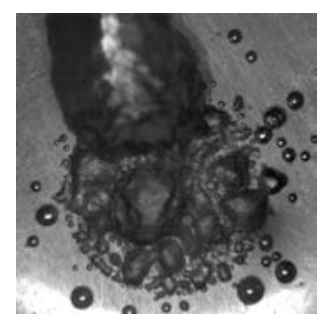

Osec.

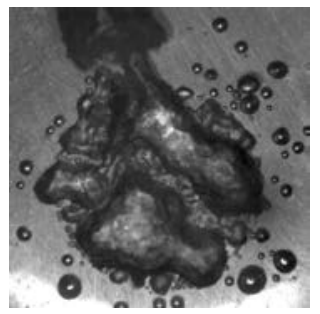

$0.004 \mathrm{sec}$.

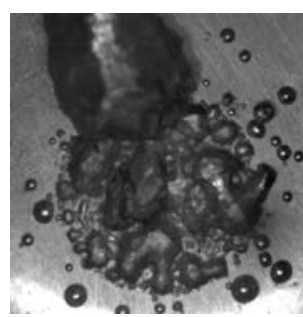

$0.001 \mathrm{sec}$.

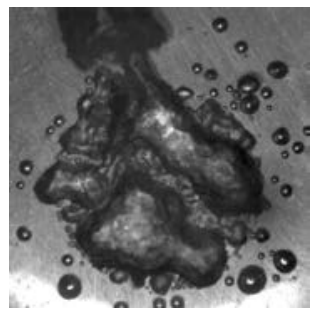

$0.005 \mathrm{sec}$.

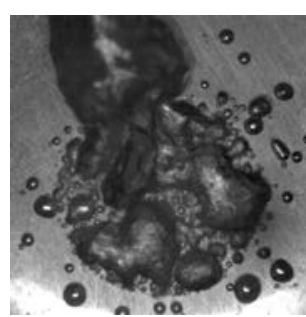

$0.002 \mathrm{sec}$

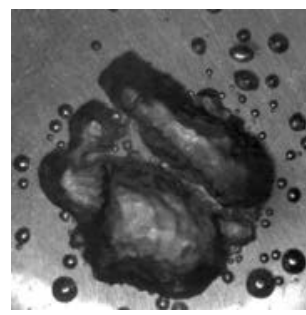

$0.006 \mathrm{sec}$

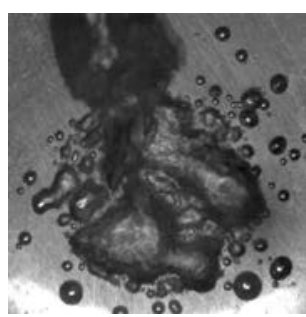

0.003 sec.

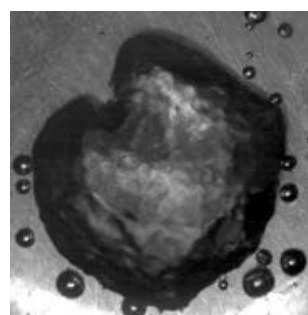

$0.008 \mathrm{sec}$.

Fig. 7 Sequential images of the boiling appearance from the detachment of the preceding vapor mass to the formation of the next vapor mass for water boiling at $2.78 \mathrm{MW} / \mathrm{m}^{2}$ at $0.8 \mathrm{MPa}$.

and the CHF is reached. For water boiling, the large vapor masses covering the heating surface begin to form at $50 \%$ of the CHF under all pressure conditions in the present experiment. The results obtained in the present experiments suggest that the occurrence of the CHF in the pressure range of the present experiments is closely related to the formation of the large vapor masses and consumption of the liquid layer beneath the vapor masses.

Figure 7 shows sequential images of the boiling behaviors from the detachment of the preceding vapor mass to the formation of the next vapor mass with water boiling at $2.78 \mathrm{MW} / \mathrm{m}^{2}$ at $0.8 \mathrm{MPa}$. After the detachment of the preceding vapor mass, a number of small coalesced bubbles develop, these coalesce further and grow to one large vapor mass. Further, it is also observed that fine primary bubbles are generated at the spaces between the coalesced bubbles (The diameter of these primary bubbles were estimated as 0.05 to $0.3 \mathrm{~mm}$ ). The liquid layer (macrolayer) thickness beneath the large vapor masses is thought to be closely related to the shape and size of the bubbles forming the vapor masses. Therefore, when the CHF is assumed to be caused by dryout of the liquid layer beneath the vapor masses, detailed examinations of the process of multiple coalescence of the primary and coalesced bubbles are indispensable to be able to quantitatively model the CHF at high pressures.

\subsection{Critical heat fluxes}

Figures 8, 9, and 10 show the CHF data for ethanol, R141b, and water measured in the present experiments. In these figures, the predicted results with Eq. (1) by Zuber $(K=0.131)$, and Lienhard and Dhir $(K=0.149)$ are also plotted. The data for ethanol (Fig. 8) show larger values than the results by Zuber, and Lienhard and Dhir, but the variations with pressure are very similar and agree well with Eq. (1) in the whole range of pressures when $\mathrm{K}$ is given as 0.19 . The data for R141b (Fig. 9) are similar to the results of ethanol, and agree with Eq. (1) with $K=0.21$. The data for water shown in Fig. 10 agree well with the predictions with Eq. (1) by Zuber, and Lienhard and Dhir at 0.1 MPa, but at higher pressures the measured CHF values are larger than the predicted values and the discrepancy increases with higher pressures. This suggests that with water it may not be possible to fit the data to Eq. (1) over the whole range of pressures just by adjusting the constant $K$, different from the CHF for ethanol and R141b.

As detailed in the Introduction, the previously reported CHF at high pressures for ethanol, hydrocarbons, and cryogens measured for horizontal and inclined surfaces of various sizes can be made to agree with Eq. (1) by adjusting $K$ to suitable values. In the present experiment, the diameter of the heating surface is $7 \mathrm{~mm}$, smaller than the surfaces used in previous studies for the measurements of CHF at high pressures, still here the CHF of ethanol and R141b agree well with Eq. (1), similar to the results of previous research.

One major difference between the physical characteristics of water and other liquids such as alcohols (ethanol), hydrocarbons, cryogens, and refrigerants (R141b), is the differences in wettability between liquid and heating surface. 


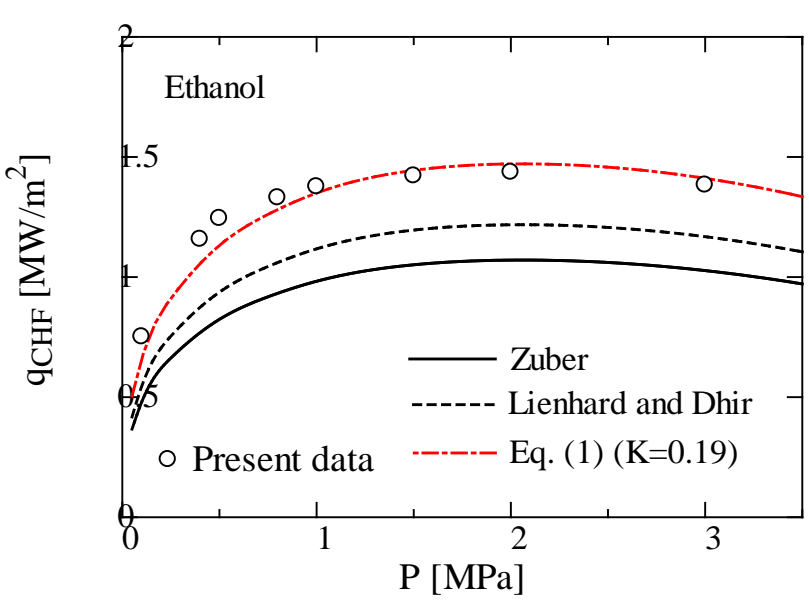

Fig. 8 CHF vs. pressure for ethanol

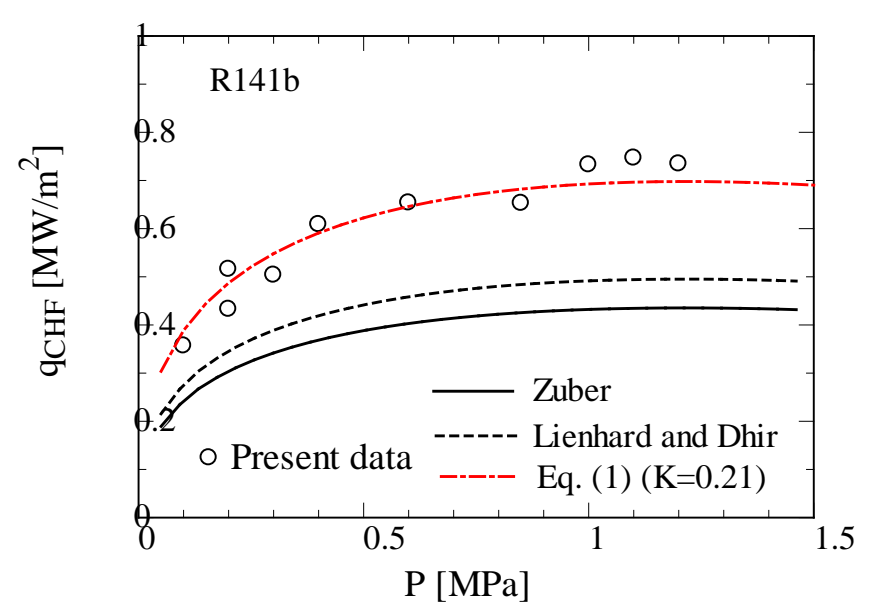

Fig. 9 CHF vs. pressure for R141b

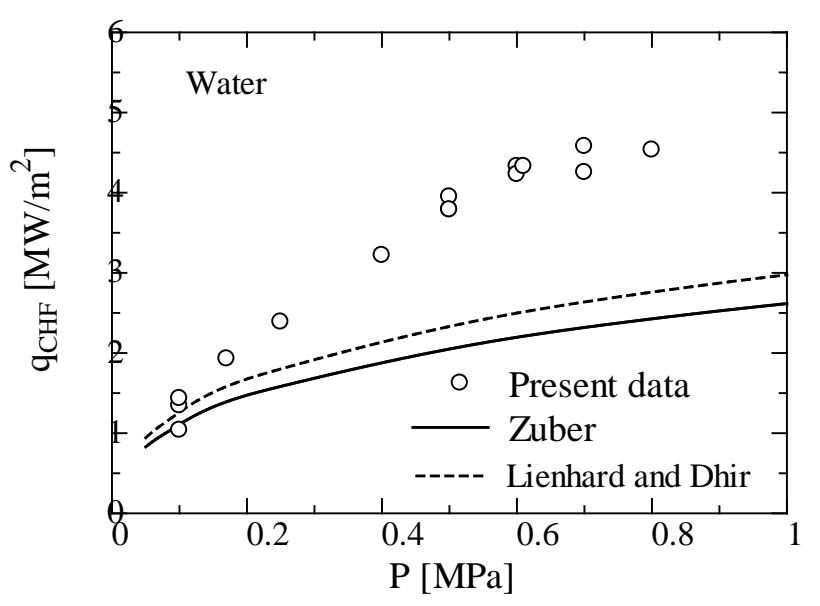

Fig. 10 CHF vs. pressure for water

At room temperature and atmospheric pressure, alcohols, hydrocarbons, cryogens and refrigerants have high wettabilities on metal surfaces, while the wettability of water on metal surfaces is generally relatively poor. In the present experiments, the static contact angle of liquid droplets (about $3 \mu \mathrm{l}$ ) placed on the heating surface (Ni-plated copper surface) measured at room temperature at $0.1 \mathrm{MPa}$ were close to $0^{\circ}$ for ethanol and R141b, and about $75^{\circ}$ for water. From this it may be surmised that the wettability of ethanol and R141b is not affected by the changes in pressure (temperature), however, the wettability of water can be expected to improve with increases in pressure, as will be further detailed below. Much research has noted that improvements in surface wettability lead to increases in the CHF. In the following, the CHF of water will be examined from the viewpoint of surface wettability under high pressure (high temperature) conditions.

Research into wettability with water at high temperatures has been reported by Bernardin et al. (1997) and Hazuku et al. (2009). Bernardin et al. measured the contact angles of water droplets on an aluminum plate in the temperature range of 25 to $175{ }^{\circ} \mathrm{C}$, and obtained the result that the contact angle, $\theta$, remains at a constant value for surface temperatures below $120{ }^{\circ} \mathrm{C}$, and that above $120{ }^{\circ} \mathrm{C}$ it decreases in a linear manner with the temperature derivative $\mathrm{d} \theta / \mathrm{d} T=-0.55 \mathrm{deg} . \mathrm{K}^{-1}$. Hazuku et al. measured the contact angles of water droplets on aluminum, stainless steel and zircaloy plates at temperatures up to $300^{\circ} \mathrm{C}$.

Figure 11 shows the data of contact angles measured by Bernardin et al. (1997) and Hazuku et al. (2009). In Fig. 11 , the data measured by the author here are also plotted, these were obtained by releasing a water droplet from a $5 \mathrm{~mm}$ height via a thin needle onto a stainless steel plate in the high pressure cell shown in Fig. 3. The pressure inside the cell was adjusted with nitrogen to a value above the saturation pressure corresponding to a desired temperature. In Fig. 11, the values of the contact angles are different at different measurements, but the temperature dependence of the data by Hazuku et al. and the present author show similar tendencies as the results by Bernardin et al.: the contact angle remains almost constant to around $120^{\circ} \mathrm{C}$, then decreases linearly with increases in temperature. The gradient of the 


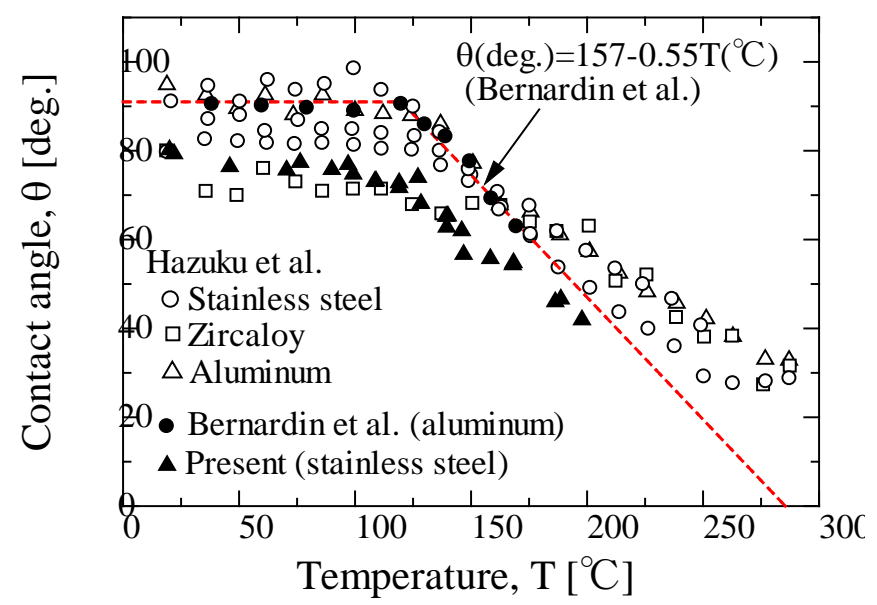

Fig. 11 Contact angles of water droplets on metal surfaces vs. temperature

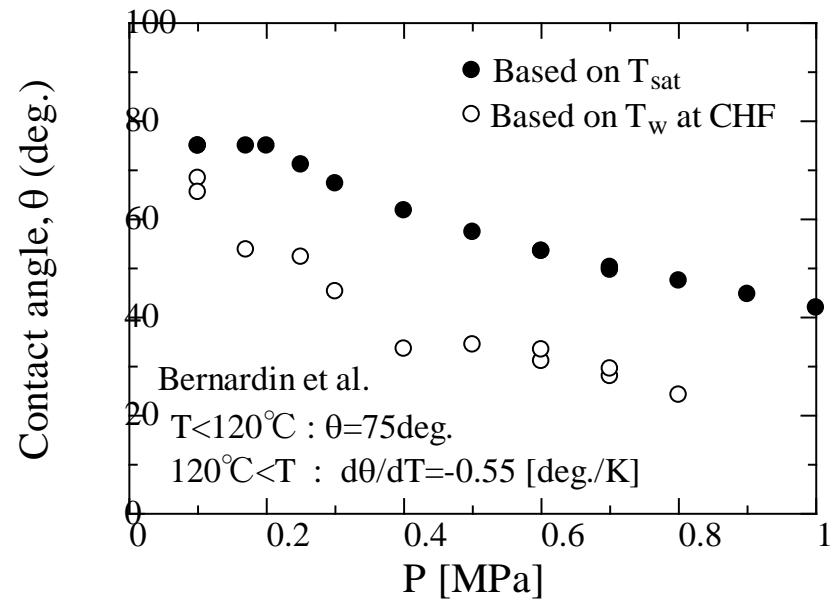

Fig. 12 Changes in contact angle with pressure, estimated from the results in Fig. 11

decrease in contact angle by Hazuku et al. moderates somewhat at temperatures above $200{ }^{\circ} \mathrm{C}$, but below $200^{\circ} \mathrm{C}$ the results by Hazuku et al. and the present author show similar tendencies to the results by Bernardin et al. $\left(\mathrm{d} \theta / \mathrm{d} T=-0.55 \mathrm{deg} . \mathrm{K}^{-1}\right)$ in the region from 120 to $200{ }^{\circ} \mathrm{C}$, regardless of the surface material. Therefore, it was assumed that the contact angle of water on the Ni-plated copper surface used in the present experiments remains at a constant value till $120{ }^{\circ} \mathrm{C}$ (the measured value at room temperature, $\theta=75^{\circ}$, was used), and that it decreases with the gradient $\mathrm{d} \theta / \mathrm{d} T=-0.55 \mathrm{deg} . \mathrm{K}^{-1}$ above $120{ }^{\circ} \mathrm{C}$. Figure 12 plots the changes in contact angle of water with pressure, estimated based on this assumption. In Fig. 12, the solid symbols $(\bullet)$ are for the contact angle based on the saturation temperature at the various pressures, and the open symbols $(\circ)$ are based on the measured surface temperature at the CHF. The contact angles based on the surface temperature at CHF (the open symbols (O)) decrease greatly as the pressure increases from 0.1 to $0.4 \mathrm{MPa}$.

Correlations for CHF incorporating the effect of the surface wettability have been proposed by Kirichenko and Chernyakov (1971), and Kandlikar (2001). Kirichenko and Chernyakov assumed that hydrodynamic instability is responsible for the occurrence of the CHF and proposed the following correlation by considering the effect of the contact angle on the instability wave length, as

$$
q_{C H F}=0.171 \rho_{v}^{\frac{1}{2}} H_{f g}\left\{\sigma g\left(\rho_{l}-\rho_{v}\right)\right\}^{\frac{1}{4}} \cdot \frac{\left(1+0.324 \times 10^{-3} \theta^{2}\right)^{1 / 4}}{\sqrt{0.018 \theta}}
$$

where $\theta$ is a static contact angle and the unit is [degree]. The Kandlikar model (2001) incorporating the effect of the contact angle on the CHF considers the lateral forces acting on a bubble attached to a heating surface. When the force arising from changes in the momentum due to evaporation at the bubble interface exceeds the forces working to maintain the bubble in place, due to gravity and surface tension, the base of the bubble (the dry area) spreads along the 


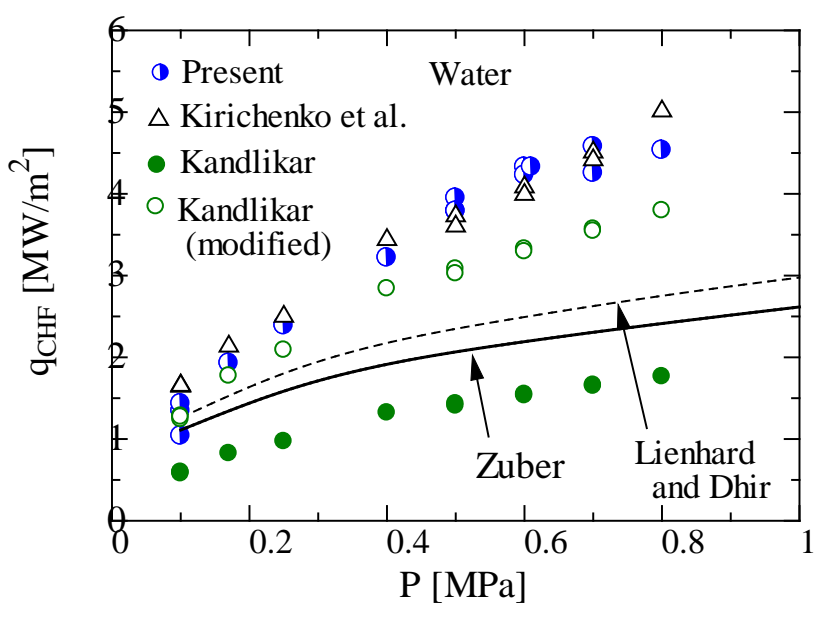

Fig.13 Plot of the present data for water with the predicted results by Eq. (2) by Kirichenko and Chernyakov (1971) and the original and modified Eq. (3) by Kandlikar (2001)

heating surface, leading to the CHF. The correlation by Kandlikar is given as

$$
q_{C H F}=\rho_{v}{ }^{\frac{1}{2}} H_{f g}\left\{\sigma g\left(\rho_{l}-\rho_{v}\right)\right\}^{\frac{1}{4}} \cdot\left(\frac{1+\cos \beta}{16}\right)\left[\frac{2}{\pi}+\frac{\pi}{4}(1+\cos \beta) \cos \phi\right]^{\frac{1}{2}}
$$

where $\beta$ is a dynamic receding contact angle and $\phi$ is the angle of inclination of the surface measured in relation to the upward position ( $\phi=90 \mathrm{deg}$. for the present measurements with the vertical surface).

Figure 13 shows comparisons of the present data for water with the predictions with Eqs. (2) and (3). The predictions with Eq. (1) by Zuber $(K=0.13)$, and Lienhard and Dhir $(K=0.149)$ are also plotted in Fig. 13. When using Eq. (3), the dynamic receding contact angle should be used for the parameter $\beta$, but these values are not known at high pressures, and the static contact angle estimated based on the measured surface temperature at the CHF (the open symbols (०) in Fig. 12) was used for both the $\theta$ in Eq. (2) and the $\beta$ in Eq. (3). According to Fig. 2 in the original paper by Kirichenko and Chernyakov (1971), where Eq. (2) is compared with the CHF for water at $0.1 \mathrm{MPa}$ measured by varying the contact angles, Eq. (2) agrees fairly well with the data within the $20^{\circ} \leq \theta \leq 60^{\circ}$ range, and predicts higher values than the data for $\theta<20^{\circ}$ and $60^{\circ}<\theta$. Further, as stated by Kirichenko and Chernyakov (1971), Eq. (2) does not apply to contact angles close to $0^{\circ}$, as it approaches infinity here. Looking at Fig. 13 with these characteristics in mind, Eq. (2) predicts larger values than the present data at $0.1 \mathrm{MPa}$, where the contact angle $\left(\theta=65.5^{\circ}\right.$ to $\left.68.4^{\circ}\right)$ is larger than $60^{\circ}$, and agrees well with the present data from 0.17 to $0.8 \mathrm{MPa}$, where the contact angles $\left(24.2^{\circ} \leq \theta \leq 53.8^{\circ}\right)$ lie in the range of $20^{\circ} \leq \theta \leq 60^{\circ}$. Eq. (3) by Kandlikar predicts considerably lower values than the present data over the whole range of pressures. The main reason for the discrepancy comes from the term in the last parenthesis on the right hand side of Eq. (3) expressing the effect of the surface orientation. With $\beta=68.4^{\circ}$ (the contact angle at $0.1 \mathrm{MPa}$ ), Eq. (3) predicts the $\mathrm{CHF}$ for a vertical surface $\left(\phi=90^{\circ}\right)$ as $40 \%$ lower than the CHF for a horizontal surface $\left(\phi=0^{\circ}\right)$. According to the results by Howard and Mudawar (1999) and Brusster (1997), where the effect of surface orientation on CHF was examined with water and FC-72, the CHF is little affected by angle of inclination and takes similar values from $\phi=0^{\circ}$ to $90^{\circ}$. Chan and You (1996) measured the CHF of FC-72 and show that the variation in CHF is about $14 \%$ in the $\phi=0^{\circ}$ to $90^{\circ}$ range. Considering these results, it is thought that Eq. (3) may overestimate the effect of the surface inclination on the CHF in the $\phi=0^{\circ}$ to $90^{\circ}$ range. To examine the relative variations of the CHF with the contact angle $\beta$, Fig. 13 plots the results with Eq. (3) multiplied by a factor of 2.2, as this agrees with the average of the present data at $0.1 \mathrm{MPa}$ $\left(1.27 \mathrm{MW} / \mathrm{m}^{2}\right)$. The predictions with the modified Eq. (3) plot fairly close to the present data.

The results shown above suggest that it is necessary to consider the effect of changes in wettability with temperature (pressure) when predicting the variation of the CHF of water with pressure.

\section{Conclusions}

The CHF was measured and boiling behaviors were observed during saturated pool boiling of ethanol, R141b, and water on a $7 \mathrm{~mm}$ diameter vertical copper surface at pressures higher than atmospheric pressure. The conclusions obtained in the present study may be summarized as follows: 
(1) For the boiling in ethanol, R141b, and water, CHF occurs accompanied by the formation of large vapor masses that cover most of the heating surface in the whole range of pressures in the present experiments. This would suggest that the trigger of the CHF at high pressures is closely related to the dryout of the liquid layer (macrolayer) formed beneath the large vapor masses.

(2) For boiling of ethanol and R141b, the variations of CHF with pressure agree well with Eq. (1) derived for infinite horizontal upward facing surfaces. For boiling of water, Eq. (1) underestimates the pressure dependence of CHF.

(3) Based on the available and the present data, the contact angle of water on metal surfaces remains almost constant to around $120^{\circ} \mathrm{C}$, then decreases linearly with further increases in temperature. When considering this temperature dependence of the contact angle, the correlation by Kirichenko and Chernyakov, which includes the effect of surface wettability on CHF, agrees well with the present data of CHF for water. Also, the correlation by Kandlicar, which also considers the effect of surface wettability, explains the variation of CHF for water with pressure qualitatively.

(4) In conclusion the results suggest the necessity to consider the effect of changes in surface wettability with temperature (pressure) when predicting the CHF of water on flat surfaces at high pressures.

\section{References}

Arik, M. and Bar-Cohen, A., Effusivity-based correlation of surface property effects in pool boiling CHF of dielectric liquids, International Journal of Heat and Mass Transfer, Vol.46 (2003), pp.3755-3764.

Bernardin, J.D. Mudawar, I. Walsh, C.B. and Frances, E.I., Contact angle temperature dependence for water droplets on practical aluminum surfaces, International Journal of Heat and Mass Transfer, Vol.40, No.5 (1997), pp.1017-1033.

Bewilogua, L. Knöner, R. and Vinzelberg, H., Heat transfer in cryogenic liquids under pressure, Cryogenics, Vol.15, No.3 (1975), pp.121-125.

Brusstar, M.J., Effects of heater orientation on the critical heat flux-1, An experimental evaluation of models for subcooled pool boiling, International Journal of Heat and Mass Transfer, Vol.40 (1997), pp.4007-4019.

Chan, J.Y. and You, S.M., Heater orientation effects on pool boiling micro-porous enhanced surfaces in saturated FC-72, Journal of Heat Transfer, Vol.118 (1996), pp.937-943.

Cichelli, M.T. and Bonilla, C.F., Heat transfer to liquids boiling under pressure, Transactions of AIChE, Vol.41 (1949), pp.755-787.

Deev, V.I. Keilin, V.E. Kovalev, I.A. Kondratenko, A.K. and Petrovichev, V.I., Nucleate and film pool boiling heat transfer to saturated liquid helium, Cryogenics, Vo.17, No.10 (1977), pp.557-562.

Dhir, V.K. and Liaw, S.P., Framework for a unified model for nucleate and transition pool boiling, Journal of Heat Transfer, Vol.111 (1987), pp.739-746.

Golobic, I. and Bergles, A.E., Effects of heater-side factors on the saturated pool boiling critical heat flux, Experimental Thermal and Fluid Science, Vol.15 (1997), pp.43-51.

Ha, S.J. and Ma, H.C., A dry spot model of critical heat flux in pool and forced convection boiling, International Journal of Heat and Mass Transfer, Vol.41, No.-2 (1998), pp.303-311.

Haramura, Y. and Katto, Y., A new hydrodynamic model of critical heat flux, applicable widely to both pool and forced convection boiling on submerged bodies in saturated liquids, International Journal of Heat and Mass Transfer, Vol.26, No.3 (1983), pp.389-399.

Hazuku, T. Hirose, Y. Hayashi, T. Pollman, A.G. Fukuhara, Y. and Takamasa, T., Effect of radiation on surface wettability under high-temperature and high-pressure environment, Transactions of Japan Siciety of Mechanical Engineers, Series B, Vol.75, No.758 (2009), pp.1911-1916 (in Japanese).

Houchin, W.R. and Lienhard, J.H., Boiling burnout in low thermal capacity heaters, ASME Paper, No.66-WA/HT-40 (1966).

Howard, A.H. and Mudawar, I., Orientation effects on pool boiling critical heat flux (CHF) and modeling of CHF for near-vertical surfaces, International Journal of Heat and Mass Transfer, Vol.42 (1999), pp.1665-1688.

Kandlikar, S.G., A theoretical model to predict pool boiling CHF incorporating effects of contact angle and orientation, Journal of Heat Transfer, Vol.123 (2001), pp.1071-1079.

Katto, Y. and Yokoya, S., Principal mechanism of boiling crisis in pool boiling, International Journal of Heat and Mass Transfer, Vol.11 (1968), pp.993-996. 
Kazakova, E.A., The effect of pressure on the maximum heat flow while boiling water in a large pool, Izvestia, AN SSSR, OTN No.1 (1949), pp.64-69 (in Russian).

Kazakova, E.A., Maximum heat flow while boiling water under high and super-high pressures, Izvestia AN SSSR LXXI, No.1 (1950), pp.53-55 (in Russian).

Kazakova, E.A., Influence of pressure on the production of the first crisis in the boiling of water on a horizontal plate, in Problems of heat transfer during a change of state, edited by S.S. Kutateladze, AEC-tr-3405 (1953), pp.86-94.

Kirichenko, Y.A. and Chernyakov, P.S., Determination of the first critical thermal flux on flat heaters, Journal of Engineering and Thermophysics, Vol.20, No.6 (1971), pp.699-703.

Kutateladze, S.S., Heat transfer in condensation and boiling, AEC-tr-3770 (1952), pp.95-113.

Lienhard, L.H. and Watanabe, K., On correlating the peak and minimum boiling heat fluxes with pressure and heater configuration, Journal of Heat Transfer, Vol.88 (1966), pp.94-100.

Lienhard, J.H. and Dhir, V.K., Hydrodynamic prediction of peak pool boiling. Journal of Heat Transfer, Vol.95 (1973), pp.152-158.

Nishio, S. Gotoh, T. and Nagai, N., Observation of boiling structures in high heat-flux boiling, International Journal of Heat and Mass Transfer, Vol.41 (1998), pp.3191-3201.

Sakashita, H. and Ono, A., Boiling behaviors and critical heat flux on a horizontal plate in saturated pool boiling of water at high pressures, International Journal of Heat and Mass Transfer, Vol.52 (2009), pp.744-750.

Stephan, K. and Abdelsalam, M., Heat-transfer correlations for natural convection boiling, International Journal of Heat and Mass Transfer, Vol.20 (1980), pp.73-87.

Sun, K.H. and Lienhard, J.H., The peak pool boiling heat flux on horizontal cylinders, International Journal of Heat and Mass Transfer, Vol.13 (1970), pp.1425-1439.

Tachibana, F. Akiyama, M. and Kawamura, H., Non-hydrodynamic aspects of pool boiling burnout, Journal of Nuclear Science and Technology, Vol.4, No.3 (1967), pp.121-130.

Theofanous, T.G. Dinh, T.N. Tu, J.P and Dinh, A.T., The boiling crisis phenomenon Part2: dryout dynamics and burnout, Experimental Thermal and Fluid Science, Vol.26 (2002), pp.793-810.

Unal, C. Daw, V. and Nelson, R.A., Unifying the controlling mechanisms for the critical heat flux and quenching, Journal of Heat Transfer, Vol.114 (1992), pp.972-982.

Zhao, Y.H. Masuoka, T. and Tsuruta, T., Unified theoretical prediction of fully developed nucleate boiling and critical heat flux based on a dynamic microlayer model, International Journal of Heat and Mass Transfer, Vol.45 (2002), pp.3189-3197.

Zuber, N., Hydrodynamic aspects of boiling heat transfer, AECU-4439, Physics and Mathematics, (1959), US Atomic Energy Commission. 